\title{
Micro-test system for rapid isolation and identification of Candida species in urinary tract infections
}

DOI: $\underline{\text { http://doi.org/10.26758/7.1.7 }}$

Nicolae Puşcaş (1), Greta Bălan (2), Olga Burduniuc (3)

(1) State University of Medicine and Pharmacy "Nicolae Testemitanu", Republic of Moldova

(2) The School of Public Health Management, Chișinău, Republic of Moldova

(3) National Centre for Public Health, Republic of Moldova

Address correspondence to: Nicolae Puscas, Department of Microbiology, State University of Medicine and Pharmacy "Nicolae Testemitanu", 26/2 Testemitanu Street Room 103, Chisinau, MD 2025, Republic of Moldova. E-mail: nicolae.puscas@usmf.md

\begin{abstract}
Objectives. We tried to create a culture medium and a method used to rapidly isolate and identify the yeasts of Candida genus.

Material and Methods. The isolation and identification of Candida genus yeasts have been accomplished using the micro-test system alongside the classical method. The strains of reference were collected from the Bacteriological Laboratory of the National Centre for Public Health.

Results. Choosing the culture medium for a prompt isolation of the germs represents a primordial element for determining the correct diagnosis. The elaborated medium increases the sensibility, selectivity and the specificity of the test used to identify Candida genus yeasts. The method involves the insertion of the material into the culture medium followed by a further incubation and identification of the Candida genus yeasts.

Conclusions. We have created a culture medium that allows a fast identification of the Candida genus yeasts. The medium is sensitive, economical and easy to use, as well as accessible for the microbiological labs of various levels. Comparing to the usual practices, the elaborated method gives us the possibility to obtain a result in 9 hours after the inoculation of the pathological material.
\end{abstract}

Keywords: Candida species; fast identification; culture medium; urinary tract infections.

\section{Introduction}

The urinary tract infections (UTIs) are among the most often infectious diseases in the medical practice. The positive prediction for UTIs clinical symptoms varies from 0,5 or lower in case of urethral symptoms for women. A significant number of UTIs evolve asymptomatic, and in case of two-year-old children the symptomatology of urinary tract infections is non-specific (Buiuc and Negut, 1999).

The frequent occurrences of mycosis, their slow and often unpredictable evolution are determined by sometimes thoughtless use of a wide range of antibiotics that have modified the biological balance between the bacteria and micromycetes in different ecological niches (Coman and Mares, 2000).

According to specialists ,conditions that predispose to candiduria include diabetes mellitus, antibiotic and corticosteroid therapy, as well as factors such as local physiology and disturbance of urine flow. Lower urinary tract candidiasis is usually the result of a retrograde infection, while renal 
parenchymal infection most often follows candidemia. In addition to asymptomatic candiduria, recognized clinical forms of candidal urinary tract infections include bladder infection, renal parenchymal infection, and infections associated with fungus ball formation" (Fisher et al., 1982).

The situation could be improved if removal of some predisposition factors is considered. The study of Malani and Kauffman found out that in almost 50\% of asymptomatic patients candiduria could be cleared by the elimination of indwelling catheters and antibiotics (Malani and Kauffman, 2007).

The diseases caused by micromycetes are not properly addressed in terms of etiopathogenesis and therapy, as they become the object of study for the practitioner or the laboratory only in critical situations when the clinical evolution of the disease or the classical treatment take a dramatic turn. (Coman and Mares, 2000; Bouza et al., 2001).

Very often, urogenital mycoses have a chronic evolution with frequent recurrences. Among Candida spp., Candida albicans is the most common infectious agent that colonize the skin, gastrointestinal tract and reproductive tract (Parveen Surain Dabas, 2013).

C. albicans is reported as the most common species that causes urinary tract infections, non-albicans Candida species are better adapted to the environment urinary tract. According to some studies, that more $50 \%$ of urinary isolates belong to non-albicans species (C. tropicalis, C. glabrata) (Sobel et al., 2011).

The incidence of candiduria depends on the setting and population that are studied and has to be carefully compared because of the above-outlined discrepancies with opinions on candiduria. The general consensus is that Candida spp. is the most frequently isolated pathogen in nosocomial urinary tract infections (Alvarez-Lerma et al., 2003, Richards et al., 2007).

There is evidence that the incidence is linked to antibiotic usage (Weinberger et al., 2003). In general, most incidence rates that based on culture results are likely underestimated, because standard urine culture is not very sensitive. Shay and Miller estimated in 2004 that the incidence of candiduria was $\sim 25,000$ cases per year in the United States.

UTIs caused by $C$. albicans are reported more frequently in catheter-associated UTIs than in non-catheter-associated infections (Achkar \& Fries, 2010).

The presence of Candida spp. on any surface of the body is abnormal, even if it does not cause any health injuries, because Candida spp. develops some toxins that provoke the weakening of the immune system (Lipovsky and Hoepelman, 1999).

If UTIs, caused by Candida spp., are not diagnosed and treated earlier, can lead to the development of severe complications (recurrent UTIs, blood infection and renal parenchyma damage, renal scarring, hypertension, renal insufficiency or renal failure) (Gelotar, Gandha and Sinha, 2012).

\section{Material and the Methods}

This study was completed using materials and standard materials recorded in the Republic of Moldova by the Ministry of Health. The study included 126 urine samples collected from the hospitalized patients with UTIs.

Sample collection: All samples were collected by midstream urine samples in a sterile container.

Sample testing: All the samples were tested as follows.

Step 1: Direct microscopy by using gram stain to identify yeast cells, budding yeast cells, hyphae and pseudohyphae. 
Step 2: Culture was done in 2 Sabouraud Dextrose Agar plates with antibiotics (chloramphenicol and cycloheximide). One plate was incubated at room temperature $\left(25^{\circ} \mathrm{C}-28^{\circ} \mathrm{C}\right)$ for mycelia growth and other at $37^{\circ} \mathrm{C}$ for yeast growth. Both plates were examined every 3rd day for a period of three weeks before declared negative.

Step 3: The growth of bacterial cultures was examined by culture characteristics, using Lactophenol Cotton Blue solution, germ tube test, sugar assimilation test.

The reference strains, C. albicans ATCC 10231, C. albicans ATCC 38248, C. albicans ATCC 36232, C. tropicalis ATCC 1369 and C. krusei ATCC 24480 were received from the Microbiological Laboratory of the National Centre for Public Health.

Data analysis was performed using statistical and computerized data processing (Epi Info 7 software) through the comparative method with the calculation of the standard errors, confidence intervals with the appreciation of differences between the experimental group and control group according to the criteria "t -Student" and significance threshold "p".

\section{Results}

During the conducted research, a new culture medium has been created in order to rapidly indicate the presence of Candida yeasts - DSMCand (Dosed Selective Medium for Candida).

This specially created environment contains the following ingredients: dry peptone broth, glucose, gelatine, the 199 medium, sodium dihydrogen, potassium hydrogen, phenol red and ciprofloxacin. The dry peptone broth, the glucose, gelatine and the 199 medium serve as a nutritional basis including all the necessary components that facilitate the growth and development of the Candida genus yeasts.

The Ciprofloxacin is the selectivity factor because it inhibits the growth and development of other microorganisms, thus ensuring the specificity of the growth environment.

The identification of the Candida genus yeasts occurs under conditions of $\mathrm{pH}$ formed of sodium dihydrogen phosphate, potassium hydrogen and the substances obtained after splitting the glucose with phenol red.

The culture medium is fixed on the bottom of a 10,0 mL vial which serves at the same time as a vessel for multiplication and identification of Candida genus yeasts. In order to identify the yeasts, $2.0 \mathrm{~mL}$ of sterile physiological serum, in which the media is dissolved and the seeds are inoculated, is added in the vial. The vial is incubated for $9-24$ hours at a temperature of $37^{\circ} \mathrm{C}$. In case Candida is present, the mixture turns from red to yellow.

We created 9 types of DSMCand with different ingredients as seen in Table 1.

Table 1. The influence of culture medium ingredients on Candida genus yeasts identification

\begin{tabular}{|c|c|c|c|c|c|c|c|c|c|c|}
\hline \multirow[t]{2}{*}{ № } & \multirow[t]{2}{*}{ Media Ingredients } & \multicolumn{9}{|c|}{ The options of media composition } \\
\hline & & 1 & 2 & 3 & 4 & 5 & 6 & 7 & 8 & 9 \\
\hline 1. & Dry peptone broth & + & - & + & + & + & + & + & + & + \\
\hline 2. & Glucose & + & + & - & + & + & + & + & + & + \\
\hline 3. & Gelatin & + & + & + & - & + & + & + & + & + \\
\hline 4. & Sodium Hidrogen & + & + & + & + & - & + & + & + & + \\
\hline 5. & Potassium dihydrogen & + & + & + & + & + & - & + & + & + \\
\hline 6. & 199 Media & + & + & + & + & + & + & - & + & + \\
\hline 7. & Phenol red & + & + & + & + & + & + & + & - & + \\
\hline 8. & Ciprofloxacine & + & + & + & + & + & + & + & + & - \\
\hline $\operatorname{Re}$ & ults of identification & $\diamond$ & - & - & $\diamond$ & $a$ & $a$ & $\mathrm{x}$ & $\mathrm{x}$ & $\Delta$ \\
\hline
\end{tabular}


Note: "+" - indicates the presence of the ingredient, "-“- the absence of the ingredient, $\mathrm{x}$ - the growth and development of yeasts that allow a 24 hours identification in incubation conditions under $37^{\circ} \mathrm{C}$; $\not a$ - doesn't allow the yeasts identification; $\diamond$ - the growth and development of yeasts that allow on 4-5 hours identification in incubation conditions under $37^{\circ} \mathrm{C}$.

Also, the sensibility of the medium according to the quantitative composition of the ingredients has been tested. Therefore, 5 different quantitative compositions of the culture medium have been created and the best option representing an optimal ratio of ingredients for a fast Candida genus yeast identification has been detected (fig. 1).

Figure 1. The ingredients report in the DSMCand

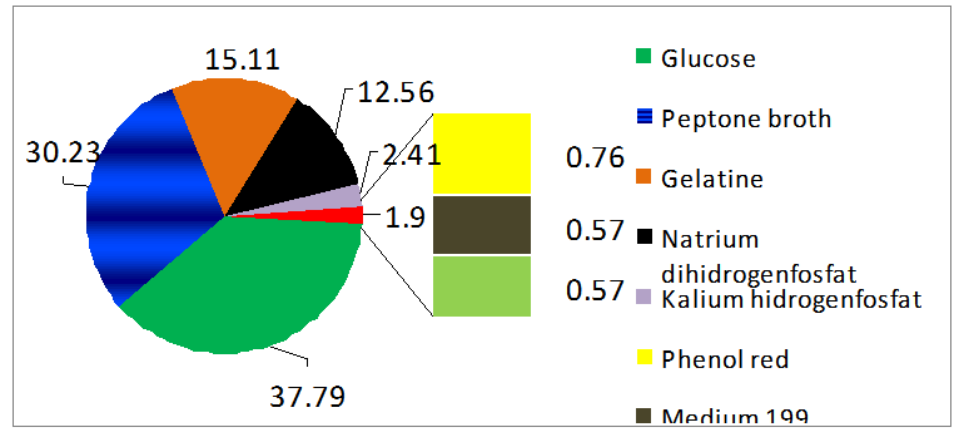

It is worth mentioning the fact that in order to prepare the right medium to conduct an analysis, the ingredients are used in small proportions, which makes the growth medium economical enough. The identification time for Candida genus yeasts depends on the initial concentration of the germs in $1 \mathrm{~mL} / \mathrm{g}$ of research material (Table 2).

Table 2. The identification time of Candida genus yeasts according to their initial concentration in the research material

\begin{tabular}{|l|c|c|c|c|c|c|c|c|c|c|}
\hline \multirow{2}{*}{$\begin{array}{l}\text { Concentration } \\
(\text { CFU/mL, g) }\end{array}$} & \multicolumn{10}{|c|}{ Identification time in hours } \\
\cline { 2 - 12 } & 1 & 2 & 3 & 4 & 5 & 6 & 7 & 8 & 9 & 24 \\
\hline $10^{1}$ & - & - & - & - & - & - & - & + & +++ & +++ \\
\hline $10^{2}$ & - & - & - & - & - & - & - & + & +++ & +++ \\
\hline $10^{3}$ & - & - & - & - & - & + & ++ & +++ & +++ & +++ \\
\hline $10^{4}$ & - & - & - & - & + & ++ & +++ & +++ & +++ & +++ \\
\hline $10^{5}$ & - & - & - & + & ++ & ++ & +++ & +++ & +++ & +++ \\
\hline $10^{6}$ & - & - & + & + & ++ & ++ & +++ & +++ & +++ & +++ \\
\hline $10^{7}$ & - & + & + & ++ & ++ & +++ & +++ & +++ & +++ & +++ \\
\hline $10^{8}$ & - & + & + & ++ & +++ & +++ & +++ & +++ & +++ & +++ \\
\hline $10^{9}$ & - & + & ++ & +++ & +++ & +++ & +++ & +++ & +++ & +++ \\
\hline The control & - & - & - & - & - & - & - & - & - & - \\
\hline
\end{tabular}

Note: "_" - the initial red color (negative result); "+" - light yellow (weakly positive result); "++" - yellow (positive result); "+++" - dark yellow (strong positive result).

The identification of the unique Candida yeasts cells is possible after 9-24 hours of incubation at $37^{\circ} \mathrm{C}$, while for the concentration of $10^{3}-10^{4} \mathrm{CFU} / \mathrm{mL}$ within $5-6$ hours of incubation at $37^{\circ} \mathrm{C}$.

In order to determine DSMCand medium selectivity, several serial experiments were performed using 4 clusters of microorganisms for 30 times. The results of the experiments prove 
that the DSMCand medium has a high selectivity towards $C$. albicans depending on the initial concentration of the Candida and microorganisms in the mixture. The identification of C.albicans in a concentration of $10^{5} \mathrm{CFU} / \mathrm{mL}$ of the following microbial associations: Candida albicans $10^{5}$ $\mathrm{CFU} / \mathrm{mL}+$ Staphylococcus aureus $10^{6} \mathrm{CFU} / \mathrm{mL}$; Candida albicans $10^{5} \mathrm{CFU} / \mathrm{mL}+$ Pseudomonas aeruginosa $10^{6} \mathrm{CFU} / \mathrm{mL}$; Candida albicans $10^{5} \mathrm{CFU} / \mathrm{mL}+$ Escherichia coli $10^{6} \mathrm{CFU} / \mathrm{mL}$ is possible after 6 hours of incubation at a temperature of $37^{\circ} \mathrm{C}$. The identification of $C$. albicans in a concentration of $10^{2}, 10^{3}, 10^{4}$ in $1 \mathrm{~mL}$ in the mixture of $S$. aureus $10^{6} \mathrm{CFU} / \mathrm{mL}$; P. aeruginosa $10^{6}$ $\mathrm{CFU} / \mathrm{mL}$; E. coli $10^{6} \mathrm{CFU} / \mathrm{mL}$ is succeeded after 9 hours (Table 3 ).

We have established the statistical accuracy of the indices assessing DSMCand selectivity in the following clusters: $C$. albicans $10^{5} \mathrm{CFU} / \mathrm{mL}+S$. aureus $10^{6} \mathrm{CFU} / \mathrm{mL}$; C. albicans $10^{5}$ $\mathrm{CFU} / \mathrm{mL}+P$. aeruginosa $10^{6} \mathrm{CFU} / \mathrm{mL} ;$ C. albicans $10^{5} \mathrm{CFU} / \mathrm{mL}+$ E. coli $10^{6} \mathrm{CFU} / \mathrm{mL}$ comparing to the combinations in which the concentration of $C$. albicans is of $10^{2}, 10^{3}, 10^{4} \mathrm{CFU} / \mathrm{mL}(\mathrm{p}<0.001)$.

Table 3. The DSMCand medium selectivity

\begin{tabular}{|c|c|c|c|c|c|c|}
\hline \multirow{3}{*}{$\begin{array}{l}\text { Evaluated associations among } \\
\text { microorganisms }\end{array}$} & \multirow{3}{*}{$\begin{array}{l}\mathrm{Nr} . \\
\exp \end{array}$} & \multicolumn{3}{|c|}{ Identification time } & \multicolumn{2}{|c|}{$\mathrm{p}$} \\
\hline & & 6 & 9 & 24 & $6-9$ & $9-24$ \\
\hline & & $\% \pm \mathrm{ESp}$ & $\% \pm \mathrm{ESp}$ & $\% \pm \mathrm{ESp}$ & hours & hours \\
\hline $\begin{array}{l}\text { Candida albicans }\left(10^{2}\right) \\
\text { Staphylococcus aureus }\left(10^{6}\right)\end{array}$ & 40 & 0 & 100 & 100 & - & - \\
\hline $\begin{array}{l}\text { Candida albicans }\left(10^{2}\right) \\
\text { Pseudomonas aeruginosa }\left(10^{6}\right)\end{array}$ & 40 & 0 & $97.5 \pm 1.42$ & $97.5 \pm 1.42$ & - & $<0.05$ \\
\hline $\begin{array}{l}\text { Candida albicans }\left(10^{2}\right) \\
\text { E.coli }\left(10^{6}\right)\end{array}$ & 40 & 0 & 100 & 100 & - & - \\
\hline $\begin{array}{l}\text { Candida albicans }\left(10^{3}\right) \\
\text { Staphylococcus aureus }\left(10^{6}\right)\end{array}$ & 40 & $10.0 \pm 0.71$ & $97.5 \pm 1.42$ & 100 & $<0.001$ & $<0.05$ \\
\hline $\begin{array}{l}\text { Candida albicans }\left(10^{3}\right) \\
\text { Pseudomonas aeruginosa }\left(10^{6}\right)\end{array}$ & 40 & $12.5 \pm 0.86$ & 100 & 100 & $<0.001$ & - \\
\hline $\begin{array}{l}\text { Candida albicans }\left(10^{3}\right) \\
\text { Escherichia coli }\left(10^{6}\right)\end{array}$ & 40 & $17.5 \pm 0.94$ & $95.0 \pm 1.53$ & 100 & $<0.001$ & $<0.05$ \\
\hline $\begin{array}{l}\text { Candida albicans }\left(10^{4}\right) \\
\text { Staphylococcus aureus }\left(10^{6}\right)\end{array}$ & 40 & $60,0 \pm 1.22$ & $97,5 \pm 1.42$ & 100 & $<0.001$ & $<0.05$ \\
\hline $\begin{array}{l}\text { Candida albicans }\left(10^{4}\right) \\
\text { Pseudomonas aeruginosa }\left(10^{6}\right)\end{array}$ & 40 & $70,0 \pm 1.26$ & 100 & 100 & $<0.05$ & - \\
\hline $\begin{array}{l}\text { Candida albicans }\left(10^{4}\right) \\
\text { Escherichia coli }\left(10^{6}\right)\end{array}$ & 40 & $65.0 \pm 1.25$ & 100 & 100 & $<0.001$ & - \\
\hline $\begin{array}{l}\text { Candida albicans }\left(10^{5}\right) \\
\text { Staphylococcus aureus }\left(10^{6}\right)\end{array}$ & 40 & $90.0 \pm 1.41$ & 100 & 100 & $<0.001$ & - \\
\hline $\begin{array}{l}\text { Candida albicans }\left(10^{5}\right) \\
\text { Pseudomonas aeruginosa }\left(10^{6}\right)\end{array}$ & 40 & $95.0 \pm 1.53$ & 100 & 100 & $<0.05$ & - \\
\hline $\begin{array}{l}\text { Candida albicans }\left(10^{5}\right) \\
\text { Escherichia coli }\left(10^{6}\right)\end{array}$ & 40 & $95.0 \pm 1.53$ & 100 & 100 & $<0.05$ & - \\
\hline
\end{tabular}

We proved the statistical veracity of selected indeces for identification of $C$. albicans in bacterial combinations during 6 - 9 hours (p 6 - 9) and 9-24 hours (p 9 - 24), where $(0.05>\mathrm{p}<0.001)$. It's worth mentioning that the DSMCand medium has a selectivity towards $C$. albicans, preventing the growth and development of other microorganisms of the mixture. 
In order to decide the sensibility of the DSMCand medium, a series of experiments have been conducted using 7 Candida genus yeasts strains with concentrations of $10^{4}$ and $10^{5}$ CFU in 1 $\mathrm{mL}$, in 12-19 repetitions. By comparison with it, two other media were used for the growth of yeasts: Agar Sabouraud with glucose and Sabouraud broth with glucose (Table 4).

Table 4. The sensibility of Candida genus yeasts identification test using DSMCand medium

\begin{tabular}{|c|c|c|c|c|c|c|c|c|}
\hline \multirow[t]{3}{*}{ № } & \multirow[t]{3}{*}{ The microbial species } & \multirow{3}{*}{$\begin{array}{l}\text { Nr. } \\
\text { of } \\
\text { repet } \\
\text { ition } \\
\text { S }\end{array}$} & \multicolumn{6}{|c|}{$\begin{array}{l}\text { The concentration of microorganisms } \mathrm{CFU} / \mathrm{mL} \\
\text { suspension, and the indication (by color) during } 6 \\
\text { hours of incubation at } 37^{\circ} \mathrm{C}(\%)\end{array}$} \\
\hline & & & \multicolumn{2}{|c|}{ DSMCand } & \multicolumn{2}{|c|}{$\begin{array}{c}\text { Agar } \\
\text { Sabouraud }\end{array}$} & \multicolumn{2}{|c|}{$\begin{array}{c}\text { Sabouraud } \\
\text { Broth }\end{array}$} \\
\hline & & & $10^{4}$ & $10^{5}$ & $10^{4}$ & $10^{5}$ & $10^{4}$ & $10^{5}$ \\
\hline 1. & C. albicans ATCC 10231 & 15 & $93.3 \pm 1.61$ & 100 & 0 & 0 & 0 & 0 \\
\hline 2. & C. albicans ATCC 38248 & 12 & 100 & 100 & 0 & 0 & 0 & 0 \\
\hline 3. & C. albicans * & 16 & $93.7 \pm 1.53$ & 100 & 0 & 0 & 0 & 0 \\
\hline 4. & C. albicans $*$ & 13 & $84.6 \pm 1.42$ & 100 & 0 & 0 & 0 & 0 \\
\hline 5. & C. albicans ATCC 36232 & 18 & 100 & 100 & 0 & 0 & 0 & 0 \\
\hline 6. & C. tropicalis ATCC 1369 & 12 & $88.9 \pm 1.63$ & 100 & 0 & 0 & 0 & 0 \\
\hline 7. & C. krusei ATCC 24480 & 19 & $94.7 \pm 1.25$ & 100 & 0 & 0 & 0 & 0 \\
\hline \multicolumn{2}{|c|}{ Total } & 102 & $93.6 \pm 0.41$ & 100 & 0 & 0 & 0 & 0 \\
\hline
\end{tabular}

Note: * - clinical strain

We established that the DSMCand medium is much more sensible than the other two (Agar Sabouraud with glucose and Sabouraud Broth with glucose): in 93,6\% of the cases, at a concentration of $10^{4} \mathrm{CFU} / \mathrm{mL}$, the identification of the Candida genus yeast was possible within 6 hours of incubation at a temperature of $37^{\circ} \mathrm{C}$; the rate of success reached $100 \%$ for a concentration of $10^{5} \mathrm{CFU} / \mathrm{mL}$.

The resulting culture medium has been kept at the bottom of the vail at a temperature of 4$7^{\circ} \mathrm{C}$ for 2 years (observational study), without changing its initial properties.

126 urine samples from the hospitalized patients with UTIs were examined. Candida genus yeasts were detected in 5 patients accounting for 3,9\% of the total sample. The results have been confirmed in $100 \%$ of the cases using the classical methods of investigation.

\section{Conclusions}

Considering the fact that the UTIs are frequent in medical practice, the improvement and development of rapid isolation and identification methods of pathogenic and conditioned pathogenic microorganisms is most welcome allowing early treatment and preventing complications.

The DSMCand medium has a high specificity and sensitivity. The method allows an identification of Candida genus yeasts within a short period of time: from 4-5 hours up to 9-24 hours, depending on the initial concentration of the germs in $1 \mathrm{~mL}$ or gram of product.

DSMCand is cheap, easy to use and accessible to any microbiological labs. The validity of DSMCand expires after 24 months. 


\section{Bibliography}

1. Achkar1, J..M., Fries, B.C., 2010. Candida Infections of the Genitourinary Tract. Clinical Microbiology Reviews, 23(2), pp. 253-273. [online] Available at: <https://www.ncbi.nlm.nih.gov/pmc/articles/PMC2863365/> [Access 15 December 2015].

2. Alvarez-Lerma, F., Nolla-Salas, J., Leon, C., Palomar, M., Jorda, R., Carrasco, N. and Bobillo, F., 2003. Candiduria in critically ill patients admitted to intensive care medical units. Intensive Care Medicine, 29(7), pp.1069-1076. [online] Available at: <http://www.ncbi.nlm.nih.gov/pubmed/12756441> [Accessed 08 September 2015].

3. Buiuc, D., Neguţ, M., 1999. Tratat de microbiologie medicală. Bucureşti: Editura Medicală.

4. Coman, I., Mareş, M., 2000. Micologie medicală aplicată. Iaşi: Editura Junimea.

5. Fisher, J., Chew, W., Shadomy, S., Duma, R., Mayhall, C. and House, W., 1982. Urinary tract infections due to Candida albicans. Reviews of infectious diseases, 4(6), pp.1107-18. [online] Available at: <http://www.ncbi.nlm.nih.gov/pubmed/6760338> [Accessed 06 September 2015].

6. Gelotar P., Kapil M. Gandha, Sinha M., 2012. Candida Urinary Tract Infection (UTI) in Paediatric Population in Jamnagar District. Medical Science, 1(6), pp. 153-154. [online] Available at: <http://www.worldwidejournals.com/international-journal-of-scientific-research(IJSR)/file.php?val=November_2012_1351879669_f0e2a_53.pdf> [Accessed 08 September 2015].

7. Lipovsky, M., Hoepelman, A., 1999. Opportunistic fungi. In: D. Armstrong \& J. Cohen., eds. Infectious Diseases, 1st edn., pp. 124-132. Mosby.

8. Malani, A. and Kauffman, C., 2007. Candida urinary tract infections: treatment options. Expert Review of Anti-infective Therapy, 5(2), pp.277-84. [online] Available at: <http://www.ncbi.nlm.nih.gov/pubmed/17402842> [Accessed 06 September 2015].

9. Parveen Surain Dabas, 2013. An approach to etiology, diagnosis and management of different types of candidiasis. Journal of Yeast and Fungal Research, 4(6). [online] Available at: <http://www.academicjournals.org/article/article1380027192_Dabas.pdf> [Accessed 06 September 2015].

10. Richards, M. J., Edwards, J. R., Culver, D. H. and Gaynes, R. P., 2007. Nosocomial infections in combined medical-surgical intensive care units in the United States. Infection Control and Hospital Epidemiology, 21(8), pp.510-515. [online] Available at: <http://www.ncbi.nlm.nih.gov/pubmed/10968716> [Accessed 08 September 2015].

11. Sobel J., John F., Carol A. Kauffman and Cheryl A. Newman, 2011. Candida Urinary Tract Infections - Epidemiology. Clinical Infectious Diseases, 52(6), pp. S.433-S.436. [online] Available at: 〈http://cid.oxfordjournals.org/content/52/suppl_6/S433.long\#ref-10> [Accessed 08 September 2015].

12. Weinberger, M., Sweet, S., Leibovici, L., Pitlik, S. D. and Samra, Z., 2003. Correlation between candiduria and departmental antibiotic use. Journal of Hospital Infection, 53(3), pp.183-186. [online] Available at: <http://www.ncbi.nlm.nih.gov/pubmed/12623318> [Accessed 08 September 2015]. 